\title{
Let Us Flatten the Infodemic Curve...
}

\author{
Balsarkar Geetha Dharmesh ${ }^{1}$
}

Published online: 25 May 2021

(c) Federation of Obstetric \& Gynecological Societies of India 2021

The Covid 19 pandemic has been raging in India since March 2020. The disease has affected people of all strata of society, and the volume of the disease, its sequela, death and suffering is unprecedented.

The novel corona virus or Covid 19 is still an enigma to healthcare providers and it is only five to ten years later we might be able to understand what right and what wrong was followed for prevention and treatment of this condition by large multicentric retrospective analysis and guidelines can be issued for the same. Till such authentic information is released, we have to resort to all the available sources of information.

Presently we are dealing with loads of information and circulars, changing every two days and write up of healthcare providers experienced in this field and even those not experienced or less experienced.
Distance learning technology or remote learning had distanced us from actual research and people believe and practice all sort of myths in the attempt to keep away the disease.

We as educated cream of the society, practising heath care providers are all being exposed to a huge amount of COVID-19 information on an hourly basis, and not all of it is factual and practical to follow for our patients. Hence we must have a mechanism to filter the information and prevent us from recommending self-made combination of prophylactic drugs; practices and monitoring techniques and protocols for admission and management.

World health organisation has taken misinformation during Covid 19 pandemic into cognisance and is working actively to educate people and stop the spread of myths.

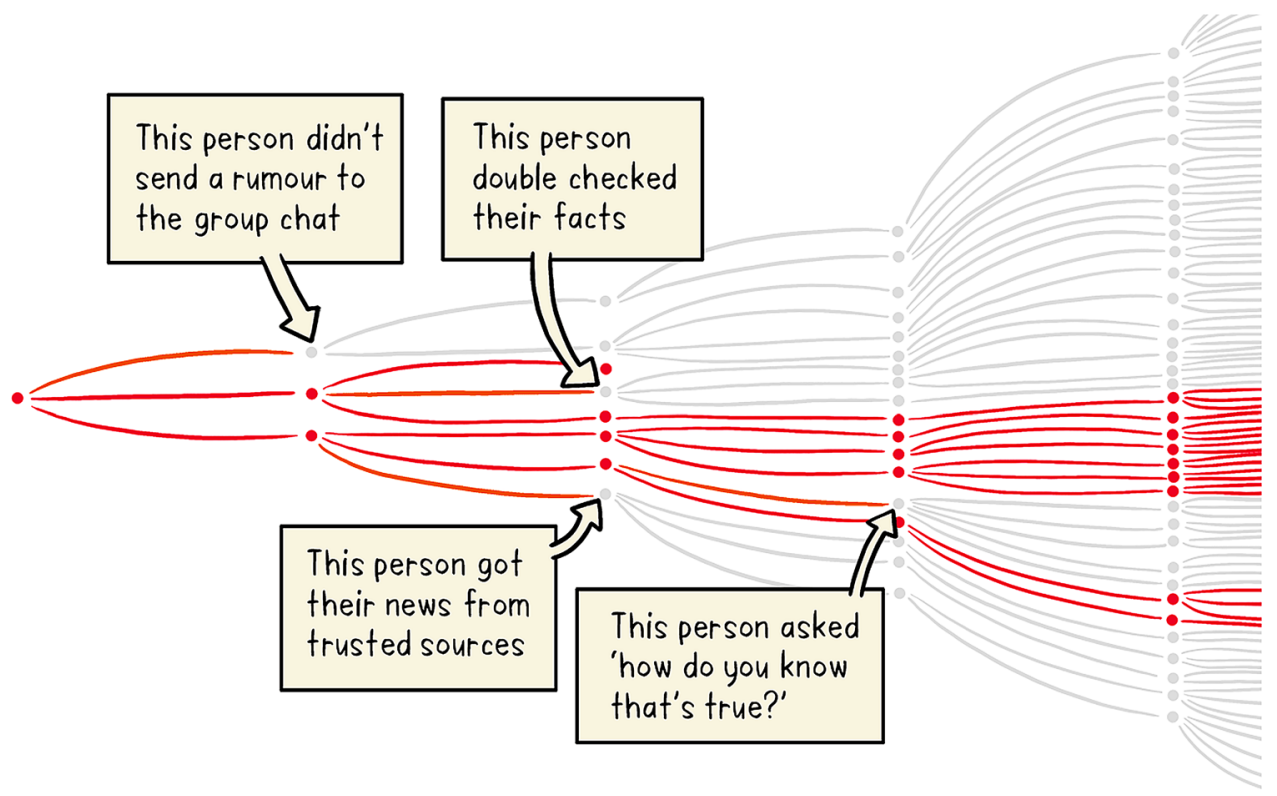

Balsarkar Geetha Dharmesh

gdbalsarkar@yahoo.com

1 Seth G.S. Medical College and Nowrosjee Wadia Maternity

Hospital, Parel, Mumbai, India 
Living in this pandemic, most of us have new words in our daily vocabulary like epidemiology, oxygen saturation, social distancing, air borne spread, isolation, covid care centre, etc.

Preventive and social branch of medicine has come into limelight due to this pandemic. Epidemiology is that branch of medical science that deals with the ways diseases are transmitted and can be controlled in a population. Now it is time to learn another new word: infodemiology, which is art of transmission of information to another person during the pandemic without doing any harm to the other person. "Primum non nocere" is a Latin phrase that means "first, do no harm" In Epidemics, Hippocrates wrote, "As to diseases, make a habit of two things- to help, or at least to do no harm."

Even the scientists all over the world are working very hard to keep up with the millions of studies and data that have come out since COVID-19 appeared. It is a challenge to stay up to date on the information details we need and how to procure them. Sharing information, the correct one for the time is a big dilemma.

There are scientific studies, medical data and publications available online. There are also official communications from central governments, state governments and health agencies around the world. Television media has reached each and every household. Then there are newspaper articles and personal messages from vloggers, bloggers, podcasters, facebook, whatsapp forwards and social media influencers. Information could also be shared by friends and family on social media or messaging apps about what worked for an individual and what did not work.

All of this is called the infodemic: a huge flood of information on the COVID-19 pandemic. Infodemiology is the study of that information and how to manage it effectively without any harm.

There are pointers one can refer to navigate this wave of information and decide who and what to trust, and what information can be passed on to benefit the individual.

1. Always take a little time to assess the source of information that has reached you. Enquire from the person who shared information whether his source was scientific. Web pages should be verified for their authenticity.

2. Delve beyond headlines to read till the small prints. Sensational and provocative headlines may be used by the author to get eye balls. Usually such mechanisms are used by unscientific people to draw attention and create confusion.

3. Identification of the author and check his credentials and place of work.

4. Check the date and time of the message or the publication as information keeps changing rapidly. Verify if it is relevant to current events
5. Examine the supporting evidence and references if they are scientific. Evaluate data as regards studies and statistics and if it is relevant to the subject in question.

6. Check your biases could be of an individual, group or community. This influences how we view what's happening around us.

7. Turn to fact-checkers like the World health organisation and government websites.

Information is defined as what we call things that are accurate to the best of our current knowledge, e.g. COVID-19 stands for coronavirus disease 2019 and is caused by the SARS-CoV-2 virus. One of the difficulties with any new pathogen, like this coronavirus, is that information changes as times passes as we learn more about the disease, its mortality, morbidity, sequela and treatment.

Misinformation is what emerges to be false information on further investigation. As a matter of fact, it is information that was not made with the only malicious intention of hurting others. Misinformation originates from someone who genuinely wants to probe a topic and cares about keeping other people healthy, safe and well. It is then further shared by others who feel the same. Everyone in the loop believes they are sharing good information-but unfortunately, that is not the case. And depending on what is being shared, the misinformation can turn out to be quite harmful to an individual or society at large.

At the farther end of the spectrum is disinformation. Unlike misinformation, this is false information created with the intention of profiting from it or causing harm to the person or situation. That harm could be to a person, a group of people, an organisation or even a country. Disinformation generally serves some agenda and can be dangerous to the society.

Misinformation and disinformation spread in the community same way like viruses. One person might share wrong news with their friends and colleagues, and then a handful of them share it further, and before anybody realises it, potentially harmful or dangerous information is spread far and wide.

In this pandemic, we can protect against COVID-19 with hand washing, social distancing and masks. Similarly we can slow down the spread of misinformation and disinformation by practising some information diligence. Before sharing something, always ask yourself some important questions:

Does this information I got make me feel good? Why am I sharing this forward?

How do I know it's true? Where did it come from?

Whose agenda might I be supporting by sharing it?

If one knows something is false, or it makes you angry, don't share it to debunk it or make fun of it. That just 
spreads the misinformation or disinformation further. The misinformation can also be reported online for misconduct.

Reliable sources to go for information are the websites of State Government, Central Government Ministry of Health or the World Health Organization.

Remember, information will change repeatedly as we learn more about the virus.

Stay safe, stay healthy and happy reading...

\section{Resources:}

- Infodemic management: a key component of the COVID19 global response-WHO Weekly epidemiological record.

- Managing the Infodemic: A critical condition for an effective global response to the COVID-19 pandemic (source WHO, 2021).

- The truth is out there, somewhere-The Lancet.

- Developing trans-disciplinary science: infodemiology, the science behind infodemic management, WHO Coronavirus disease (COVID-19) Situation Report-169.

Publisher's Note Springer Nature remains neutral with regard to jurisdictional claims in published maps and institutional affiliations.

\section{About the Author}

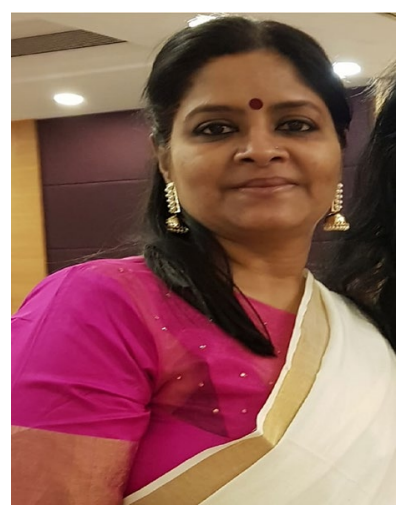

Balsarkar Geetha Dharmesh is a Professor at Seth G. S. Medical College and Nowrosjee Wadia Maternity Hospital, Mumbai, India. She is a Clinical Secretary of Mumbai Obstetrics Gynecology Society, Vice President of Menopause Society, Mumbai Branch, President of AMWI, Mumbai Branch, and Editor-InChief, Journal of Obstetrics and Gynecology of India, FOGSI Journal. She has undergone training for the PPIUCD program and is also the faculty member of many training programs as well. She has over 18 years of teaching experience and is actively working on FIGO-FOGSI Project of PPIUCD in India. She is a recipient of the prestigious Hargobind Foundation for the study of Fetal Medicine in 2008 at St. George's Hospital, London. 